ORI?L/CSD--99

DE\&4 016551

\title{
RETADD-II: A Long Range Atmospheric Trajectory Model with Consistent Treatment of Deposition Loss and Species Growth and Decay
}

\author{
B. D. Murphy \\ S. Y. Ohr \\ C. L. Begovich
}

Date of Issue-August 1984

COMPUTER SCIENCES DIVISION

at

Oak Ridge Nationel Laboratory

Post Orfice Box X

Oak Ridge, Tennessee 37831

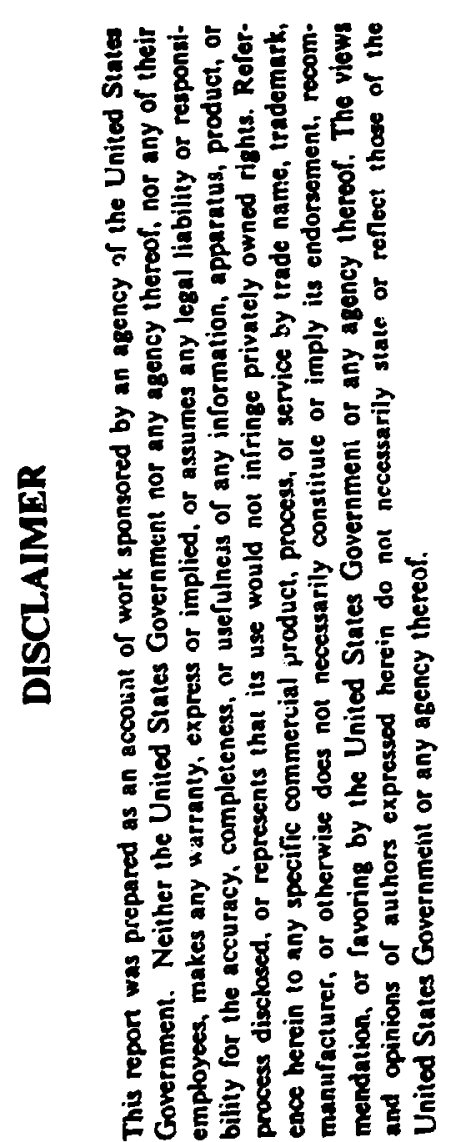

\section{MARTIN MARIETTA ENERGY SYSTEMS, Inc. operating the \\ Oak Ridge Gaseous Diffusion Plant Oak Ridge National Laboratory \\ Oak Ridge Y.12 Plant Paducah Gaseous Diffusion Plant \\ under Contract No. DE-AC05-840R21400 \\ for the \\ U.S. Department of Energy}

This work was sponsored by the iffice if Radiation Programs U.S. Environmental Protection Agency under Interagency Agreement No. EPA-AD-87-F-2-A 106 with the Department of Energy. 
Although the research described in this report has been funded wholly or in part by the United States Environmental Protection Agency through agreement \#AD-89-F-2-A106 (formerly 78-D-X0394) with Oak Ridge Nationa! Laboratory, it has not been subjected to the Agency's required peer and policy review and therefore does not necessarily reflect the views of the Agency and no official endorsement should be inferred. 


\section{CONTENTS}

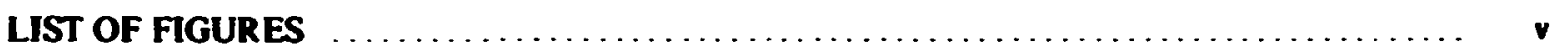

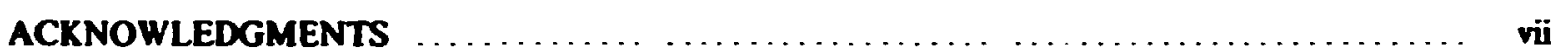

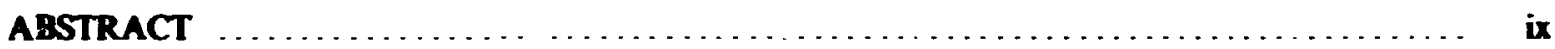

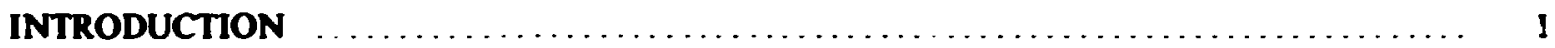

OVER VIEW OF TRAJECTORY MODEI.ING $\ldots \ldots \ldots \ldots \ldots \ldots \ldots \ldots \ldots \ldots \ldots \ldots \ldots \ldots \ldots$

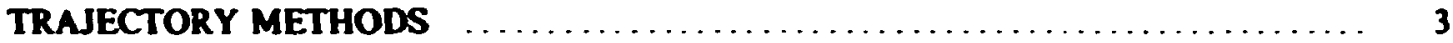

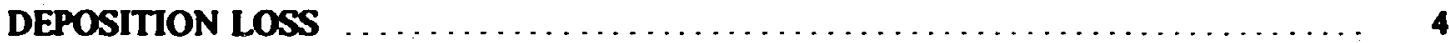

THE OVERALL DECAY PROCESS $\ldots \ldots \ldots \ldots \ldots \ldots \ldots \ldots \ldots \ldots \ldots \ldots \ldots \ldots \ldots \ldots \ldots$

THEORY OF PLUME SPECIES EVOLUTION

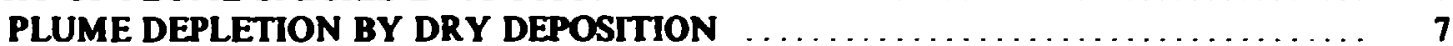

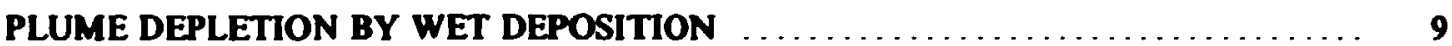

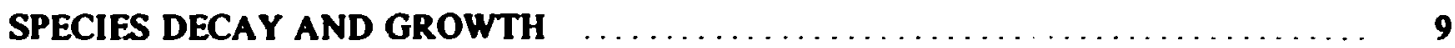

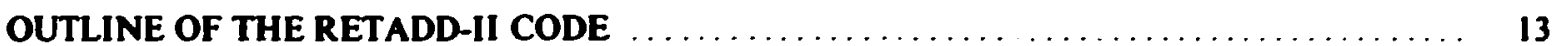

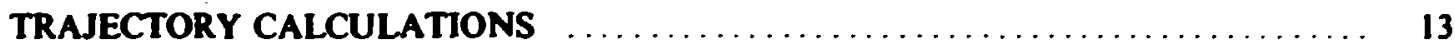

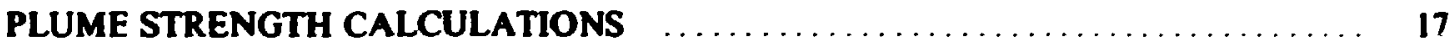

ATMOSPHERIC DISPERSION CALCULATIONS $\ldots \ldots \ldots \ldots \ldots \ldots \ldots \ldots \ldots \ldots \ldots \ldots \ldots$

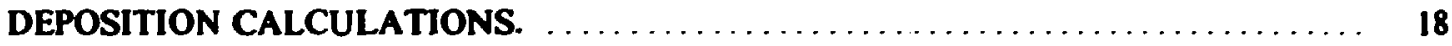

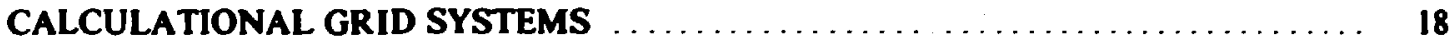

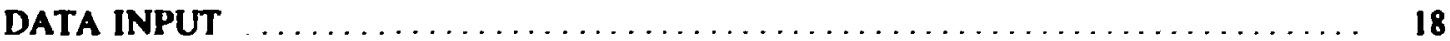

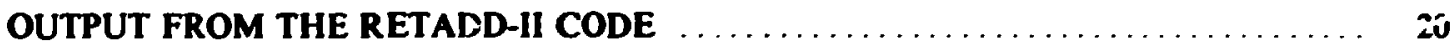

DISCUSSION OF THE RETADD-II SUBROUTINES $\ldots \ldots \ldots \ldots \ldots \ldots \ldots \ldots \ldots \ldots, 22$.

APPENDIX A - STORAGE FORMAT OF UPPER-AIR WIND DATA $\ldots \ldots \ldots \ldots \ldots \ldots \ldots, \quad 25$

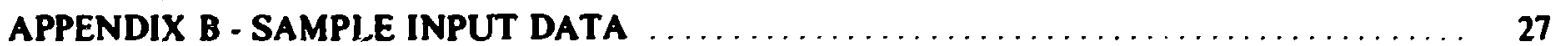

APPENDIX C - SAMPLE OF JCL USED WITH RETADD-II $\ldots \ldots \ldots \ldots \ldots \ldots \ldots \ldots \ldots$

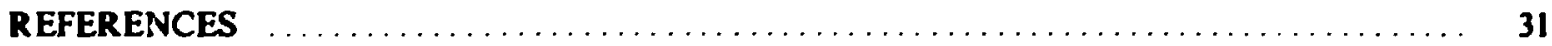




\section{LIST OF FIGURAS}

Fig. 1. Schematic representation of the codes in the Computerized Radiological Risk................2 Investigation System (CRRIS).

Fig. 2 A simple exponential decay in time is compared with a decay which is .8 of the form of that due to dry deposition. The dashed line is an approximation to the iatter curve with which it coincides periodically. In the deposition decay modeling these points of coincidence are the points at which wind trujectory updates are calculated.

Fig. 3. Plume strength as a function of travel time for sources at various beights. .10 Note that the plume strength of the ground lerel source is strongly depleted in the early stages of travel.

Fig. 4. Geometry of Distance and Alignment Factor calculation. .15

Fig. 5. The subprograms of the RLTADD code. 


\section{ACKNOWLEDGMENTS}

The authors wish to acknowledge the help and support of all who worted on the CRRIS project hoth at Oak Ridge National Laboratory and at the Environmental Protection Agency. For technical inpest from C. F. Baes III, C. W. Miller and C. B. Nelson, the authors are particularly grateful.

The typesetting and word processing services of Ms. Bobbie R. Roth were invaluable in preparing this document and in responding to the many changes and revisions which occurred during its formulation. 


\begin{abstract}
AESTRACT
A versatile model is described which estimates long-range atmospheric dispersion based on plume trajectories. This model allows the treatment of the dispersal from a source at an arbitrary height while taking account of plume depletion by dry and wet deposition togethe: with the decay of material to successor species. The plume depletion, decay and growth equations are solved in an efficient manner which can accommodate up to cight pollutants (i.e. a parent and seven serial decay produrts). The code is particularly suitable for applications involving radioactive chain decay or for cases involving chemical species with successor decay products. Arbitrary emission rates can be specified for the members of the chain or, as is commonly the case, a sole emission rate can be specified for the first member. The code uses readily available upper-air wind data for the North American contisent and it is therefore intended for the estimation of regional or continental scale dispersion patterns. This code is one of a group of codes, the Computerized Radiological Risk Inves, ization System (Baes \& Miller, 1981), designed to simulate the transport of radiontclides through environmental pathways.
\end{abstract}




\section{INTRODUCTION}

This report describes the computer code RETADD-II which mode's the long range dispersal of atmospheric pollutants and in particular radionuclides. RETADD-II is one of a group of codes that simulate the transport of radionuclides through environmental pathways and which calculate resulting health impacts. These codes were developed with funding provided by the U.S. Environmental Protection Agency (EPA) which, upon assuming regulatory authority for nuclear effluents covered by the Clean Air Act of 1977, launched an extensive review and revision of models that simulate environmental transport of radionuclides and which calculate resulting health impacts.

The system of codes to which RETADD-II belongs is known as the Computerized Radiological Risk Investigation System, or CRRIS (Baes and Miller, 1981). The relationships within this system are shown in Fig. I and a brief description of the purpose of the various codes will now be given.

PRIMUS (Hermann et al., to be published) is a pre-processing code which accesses a data base of decay data (Kocher, 1981), and determines all radionuclides in a decay chain which must be considered in transport, dose and risk calculations by other codes of the CRRIS system.

ANEMOS (Miller, Begovich and Hermann, to be published) is a short range $(<100 \mathrm{~km})$ Gaussian plume atmospheric dispersion code which calculates radionuclide activities in air at ground level and ground deposition rates on a circular grid.

TERRA (Baes et al., to be published) estimates concentratiuns of radionuclide chains in four vegetable and produce categories, four cattle feed categories, irrigated and non-irrigated soils, beef and milk.

ANDROS (Begovich, Ohr and Chester, to be published) combines environmental radionaclide concentrations with population estimates, food and air consumption rates, and dose and risk factors to calculate population and average individual doses and risks from the source term supplied to PRIMUS, ANEMOS or RETADD-II. 
ORNL- OWG 81-7083A

COMPUTERIZED RADIOLOGICAL RISK INVESTIGATION SYSTEM

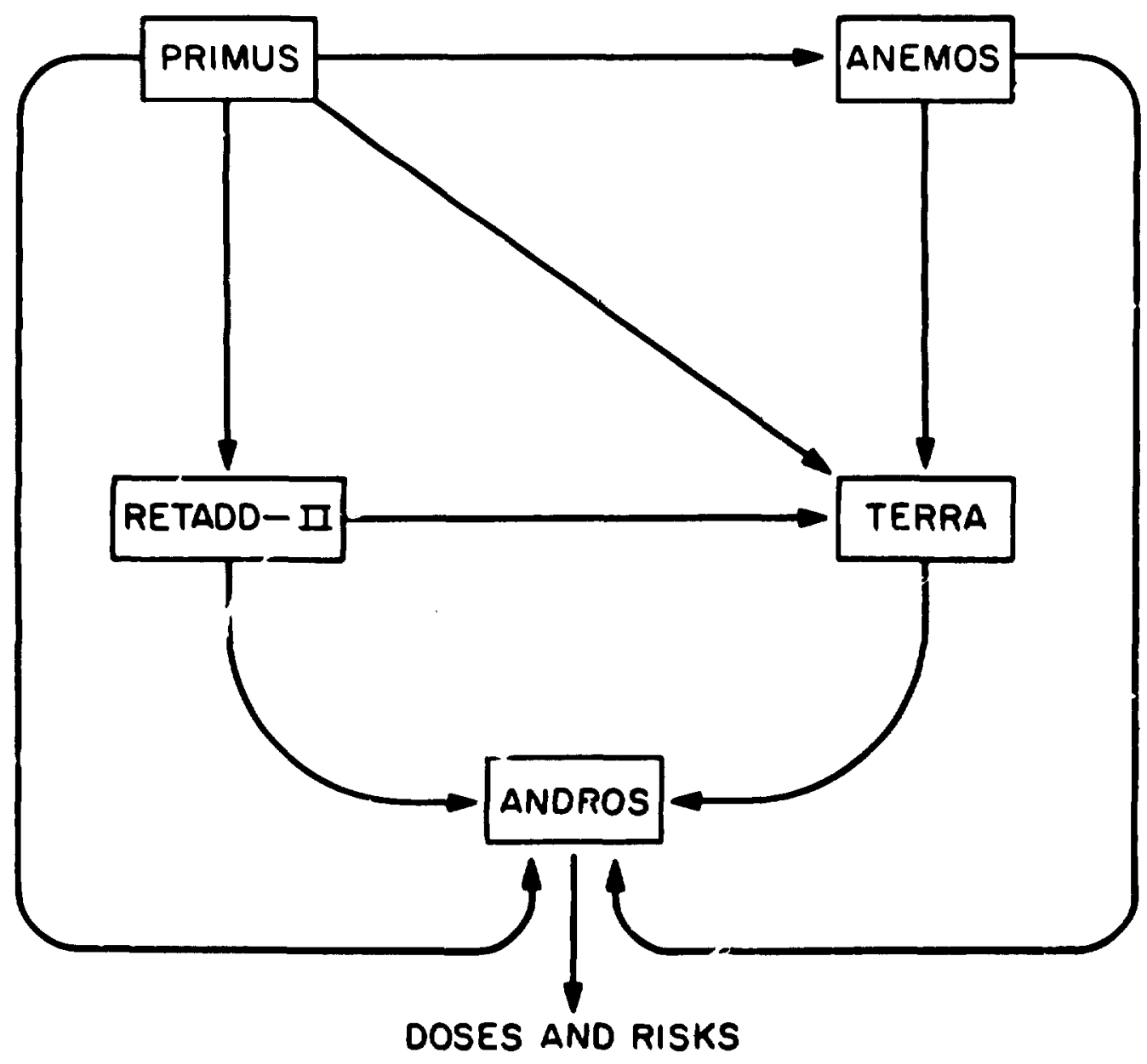

Fig. 1. Schematic representation of the codes in the Computerized Radiological Risk Investigation System (CRRIS). 


\section{OVERVIEW OF TRAJECTORY MODELING}

Long range atmospheric transport is $t=i n g$ better studied in recent times partly because the short range problem is somewhat und.rstood and party because of the realization that effects occurring at large downwind distances can also he of interest. These effects include chronic low level exposure problems and problems arising from the creation of secondary species during long distance transport of the primary material.

The present work arose out of a need to study the !ong-range atmospheric transport of radionuclides (or other pollutants) as it applies to one part of a sequence of events which have an end effect on man. In the initial parts of this sequence, transport in the atmosphere is important. Transport over short distances is generally of greatest importance for such a situation because of the occurrence of the highest concentrations of an effluent near to the source. However, long-range transport becomes important when a number of widely placed sources must be considered simultaneously and/or when chronic low-level exposure or successor species generation come into play.

The capabilities and limitations of long-range transport modeling techniques are not as well understood as in a case of short-range transport. The reader is referred to review papers (Bass, 1980, Eliasser., 1980), which give indications of the types of modeling approaches wr:ch are currently in existence for iong-range transport. It should be kept in mind that verification of long-range models is difficult and ir. many cases one can do little more than scrutinize the scientific principles on which a given model is corstructed. The model described here is intended for t. e purpose of calculating long-term averages (i.e., a r.onth or longer). We feel that long-range transport calculations for short perids of time are much less reliable. A recent article (Fisher, 1983) claims that the modeling of annual diposition patterns for sulphur pollutants is well understood, whereas the modeling of daily patterns is not considered to be practical.

\section{TRAJECTOKY METHODS}

Approaches to the long range transport modeling problem which fall under the category of trajectory methods operate by calculating the trajectories followed by material released from a source. These trajectories are computed from segments determined by the local wind vector. The trajectory determines the locus of a puff centroid (or plume centerline) and lateral and vertical diffusion is superimposed. The approach of Heffter et al., (1975) is a typical trajectory modeling approach. The ORNL code RETADD (Begovich, Murphy and Nappo, 1978) is based on the Heffter code. Anotier well-known trajectory model is MESODIF (Start and Wendell, 1974).

The current corle came about because of shoricomings in the available approaches using the trajectory techniques. These shortcomings involve the proper treatment of dry depusition and conversion to successor species. For instance, the Heffter codes (Heffter et al, 1975 and Heffter, 1980) assume a ground-!evel source. As will be shown below, such an assumption will over-estimate plume depletion in the case of an elevated source. There is also a need $t ;$ account for the dispersal of a pollutant which may give rise to a number of successor species involving decay by radioactive or chemical transformation together with loss of plume material die to deposition. This need has not been addressed in a satisfactory manner in any of the available trajectory codes of which the authors are awarc. The present code approaches these problems in the manner outlined by Murphy and Nelson (1983).

The model to be described here makes use of upper air wind data available at roughly 100 locations in the continental U.S. The model operates by allowing puffs of material to be emitted four times per day. These puffs are constrained to follow trajectories made up of three hour segments. These three hour segments are obtained from interpolated wind vectors using the newest avaiiable six hourly upper air wind data. These data are updated every six hours. However, it is only every 12 hours that all of the stations report, i.e., at $O Z$ and $12 Z$. ( $Z$ in this context refers to Greenwich Mean Time). At the intervening times $(6 \mathrm{Z}$ and $18 \mathrm{Z}$ ) about one-third of the stations report. As the puffs follow the trajectories, they grow b: lateral and vertical diffusion. With a source having an average cmission rate of $O$ units of material per second the process is described by the following equation for average ground level concentration (in units $\left./ \mathrm{m}^{3}\right)$. 


$$
x(x, y)=\frac{Q}{\pi \sigma_{y} \sigma_{z} u} \exp \left\{-1 / 2\left(\frac{y}{\sigma_{y}}\right)^{\gamma}\right\} \exp \left(-1 / 2\left(\frac{h}{\sigma_{z}}\right)^{\lambda}\right\}
$$

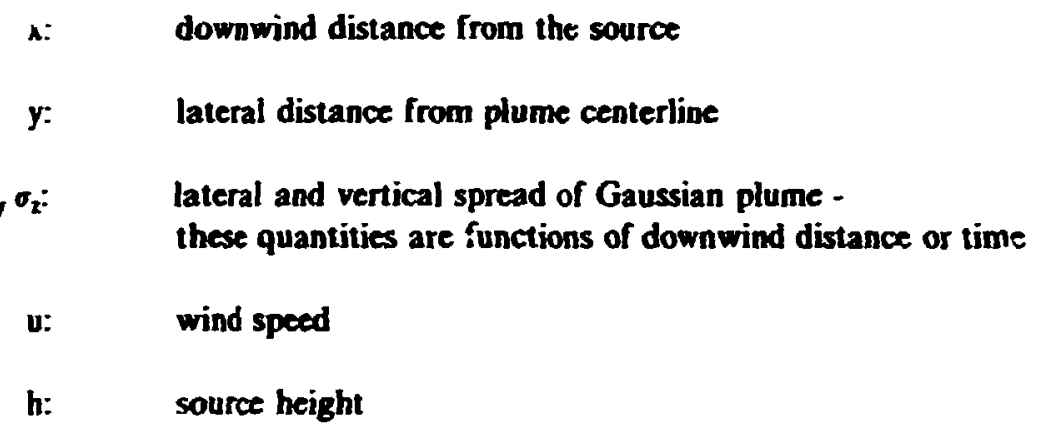

These diffusion processes are parameteized in the model as $\sigma=\sqrt{2 K t}$ where $K$ is a diffusion coefficient which must be specified. The rate at which such diffusion occurs is a subject which is being actively debated at present and users of the code are encouraged to employ different parameterizations as they see fit. The vertical and horizontal diffusion processes are summarized by Draxler (1979) and Gifford (1977) respectively. Since the code is primarily intended to estimate long term averages we do not feel that the lateral diffusion probiem is very critical since the large scale motion of the wind will be the main contributor to the dispersion process.

As we have indicated RETADD-Jl builds on and is an extension of RETADD (Begovich, Murphy, and Nappo, 1978). The major differences between the present code and RETADD a-e that a) an elevated source can be handled satisfactorily. b) dry deposition can be handled for a source at an arbitrary height, and c) growth and decay (including deposition loss) of a chain of species involving a parent and a number of daughters can be handled.

\section{DEPOSITION LOSS}

In Eq. (1), $Q$ is the amount of material emitted from the source per unit time. This is variously referred to as source strength or plume strength. As formulated, Eq. (I) assumes that all of this material remains aloft indefinitely. In fact, material deposits on the ground and this process is usually treated by assuming that $Q$ is a function of travel time of the plume, i.e., the depleted source strength concept ( $V$ an der Hoven, 1968).

Integrating out the $y$ dependence in Eq. (1) and assuming a deposition velocity of $v_{d}$ we have that the deposition rate between $x$ and $x+d x$ is

$$
\sqrt{\frac{2}{\pi}} \frac{Q V_{d}}{\sigma_{2} u} \exp \left\{-1 / 2\left(\frac{h}{\sigma_{2}}\right)^{2}\right\} d x
$$

The total amount of material in the plume between $x$ and $x+d x$ is Qdt.

Thus,

$$
\frac{d Q}{Q}=-\sqrt{\frac{2}{\pi}} \frac{v_{d}}{\sigma_{2}} \exp \left\{-1 / 2\left(\frac{h}{\sigma_{3}}\right)^{2}\right\} d t
$$

or

$$
Q(l)=Q_{0} \exp \left\{-\sqrt{2 / \pi} V_{\beta} \int_{0}^{\prime \exp \left(-1 / 2\left(h / \sigma_{2}\right)^{2}\right]} \sigma_{2} d t\right\}
$$


In solving for $Q(t)$, one approach which we have used is to choose a number of representative source heights and for a given form of $\sigma_{2}$ calculate the plume depletion at various travel times by evaluating the integral in (2) numerically. Thiese results cail then be stored and need not be calculated each time the model is run. This, of course, limits one to a given functional form for $\sigma_{z}$. However, such a technique does solve part of the problem, i.e., the $h$ dependence, when one recognizes that $h$ is never known very accurately and a representative set of values will in many cases suffice.

If one can assume $h=0$, i.e., a ground level source, the integral is quite manageable and one has

$$
Q(t)=Q_{0} \exp \left\{-\frac{2 V_{d} l^{h /}}{\left(\pi K_{2}\right) t_{2}}\right\}
$$

This is the approach adopted by Begovich et al. (1978) and by Heffter et al. (1975).

\section{THE OVERAI.L DECAY PROCESS}

Even assur ling a ground level source, however, a problem remains. From Eq. (3) one sees that the deposition removal is of the form of $e^{a t^{*}}$ whereas chemical or radioactive decays will be of the form of $e^{\text {fth }}$. In general, plume decay due to dry depositon effects cannot be considered to be in the form of a simple exponential. Note, however, that wet deposition is generally considered to be a simple exponential procese (Slinn, 1978). In light of these iacts it would be desirable to be able to cast the dry deposition process in the form of a simple exponential. The approach which is outlined below equates the dry deposition removal with an equivalent simple exponential decay. This process is repeated periodically as wind trajectories are updated. 


\section{THEORY OF PLUME SPECIES EVOLUTION}

The present model operates by updating trajectories at certain specified points in time. The deposition decay problem has therefore been addressed by solving for the removal over the time intervals between updates and then replacing this removal by an equivalent exponential term. Thus one obtains the correct solution each time the wind information is updated.

\section{PLUME DEPLETION BY DRY DEPOSITION}

In Fig. 2 are shown the depletion of a source due to deposition together with depletion by a simple exponential process. Since one updates trajectories in time, plume strength need only to be calculated at various points on the curve. The curve can then be fit with the equivalent exponential decay. With this equivalent exponential removal term, dry deposition can be treated in the same manner as first orde: chemical transformation or radioactive decay. This allews treatment of the total behavior of the piume with one consistent formalism.

It remains to calculate the effective removal constant for the dry deposition part of the process. The, deposition process can be approximated by a succession of simple exponential rrmovals. In the limit this becomes

$$
\ln \frac{Q_{i}}{Q_{i-1}}=\int_{t}^{t_{-1}}-\lambda(t) d t
$$

The form of $\lambda(t)$ can be seen by insnection of Eq. 2 to be

$$
\lambda(t)=\sqrt{\frac{2}{\pi}} V_{d} \frac{\exp \left[-\frac{1}{2}\left(h / \sigma_{z}\right)^{2}\right]}{\sigma_{z}} .
$$

Now, assuming $\lambda(t)=a^{b-1}$ it follows that

$$
\ln \frac{Q_{i}}{Q_{i-1}}=-\frac{\lambda_{i} l_{i}-\lambda_{i-1} l_{i-1}}{6}
$$

or,

$$
\lambda_{i}^{d}=\frac{\lambda_{i} t_{i}-\lambda_{i-1}}{b\left(t_{i}-t_{i}-1\right)}
$$

where

$$
b=\frac{\ln \left(\lambda_{i} / \lambda_{1-1}\right)}{\ln \left(t_{i} / t_{t-1}\right)}+1
$$

$\lambda_{i}^{d}$ is now the removal rate "constant" due to deposition.

If $b=0$ thcre is a separate solution.

$$
\ln \frac{Q_{1}}{Q_{1-1}}=-\lambda_{1} t_{1} \ln \frac{t_{1}}{t_{i-1}}
$$




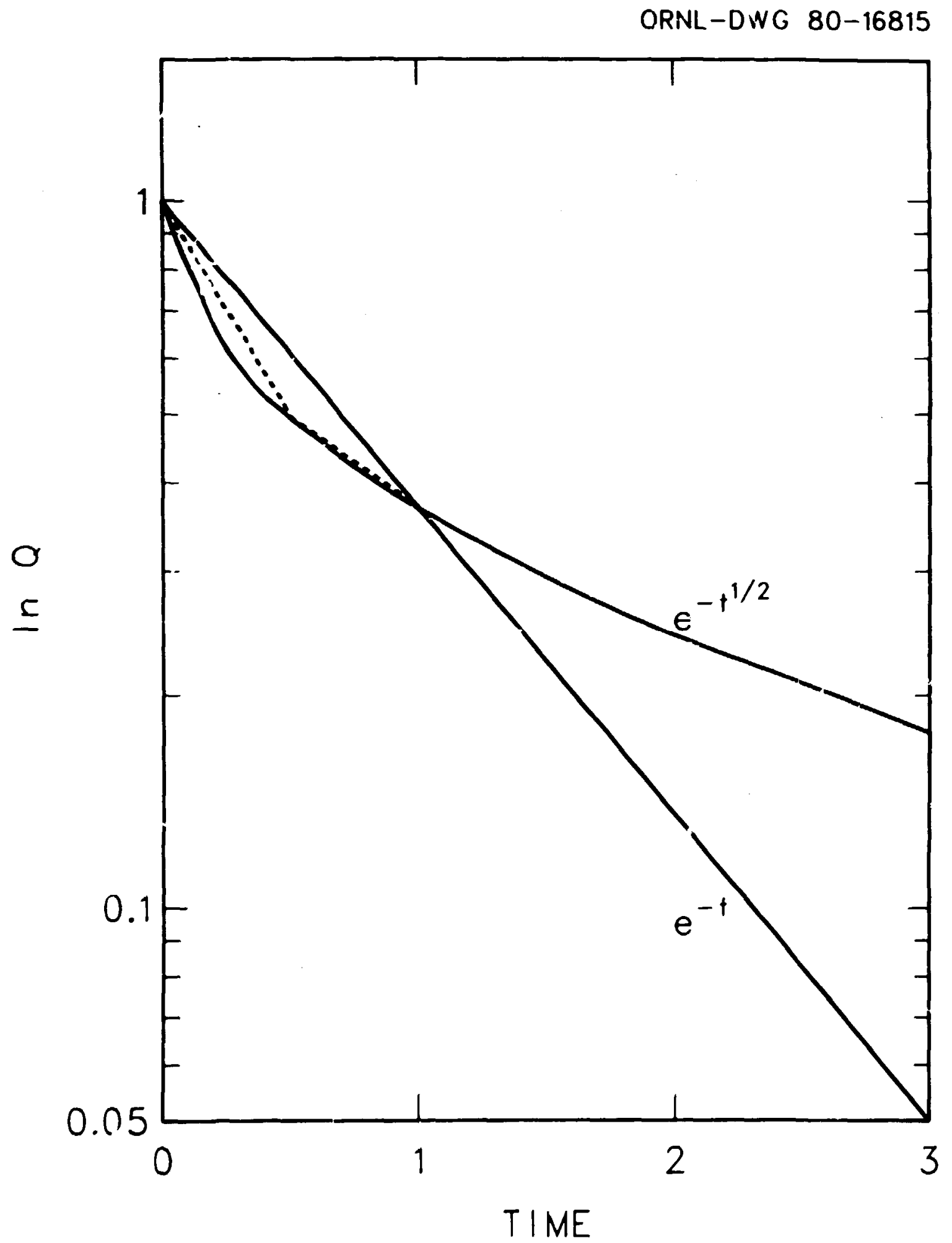

Fig. 2. A simple exponential decay in time is compared with a decay which is of the form of that due to dry deposition. The dashed line is an approximation to the latte: curve with which it coincides periodically. In the deposition decay modeling these points of coincidence are the points at which wind trajeciory updates are calculated. 
In practice, we have not encountered this case. Thus, the deposition removal is expressible in terms of $\lambda$ and $t$ at the limits of integration and cast into the form of a removal constant. If the deposition removal constant is calculated for any time period for any one species then all species in the plume can similarly be treated for that same time period. It can be seen from Eq.(2) that their removal constants differ onl; by a factor $V_{d}$

For a species having a deposition velocity of $0.01 \mathrm{~m} / \mathrm{s}$ the above technique was used to calculate plume strength as a function of travel time. In Fig. 3 the results for trio source heights, $200 \mathrm{~m}$ and $500 \mathrm{~m}$, are shown as well as the result obtained by assuming a ground level source (Eq. 3). As can be seen, the assumption of a ground level source will seriously deplete the plune in the early stages of travel and such an assumption should not be employed if the source, in fact, is not at ground level.

\section{PLUME DEPLETION BY WET DEPOSTION}

Wet removal of material from the plume is treated by invoking the concept of a washout ratio. The washout ratio is the concentration of the material in the precipitation to that in the air and it must be supplied with the input data. Washout ratio can be defined in other ways (see, e.g. Hanna, Briggs and Hosker, 1982) and in reading the literature one needs to be aware of the different definitions. As used here, washout ratio is concentration ratio in tisise of mass per unit volume. To calculate wet deposition rate on the ground one can define a wet deposition velocity which can be used analogously to the dry deposition valocity. If $W$, is the washout $r$ tio and $\mathbf{P}$ is cecripitation rate, thes, the wet deposition velocity is given by

$$
V_{w}=W_{r} P
$$

Plume depletion via wet deposition can be treated as an expinential decay process with a decay constant given by

$$
\lambda^{w}=W, P / L
$$

where $\mathrm{L}$ is the depth of the wetted plume layer. More detailed discussious of the modeling of the wet deposition process are contained in Slinn (1978) and Hanna, Briggs and Hosker (1982).

\section{SPECIES DFCAY AND GROWTH}

Putting together all removal processes, the total removal rate constant for nuclide $i$ is described by

$$
\lambda_{l}=\lambda_{i}^{r}+\lambda_{i}^{d}+\lambda_{i}^{w}
$$

where $\lambda_{l}^{r}$ is the radiological decay constant and $\lambda_{l}^{d}$ and $\lambda_{l}^{\prime \prime}$ have been defined above.

Assume there are a number of species in the plume which are serially related to one another by means of a decay chain. For any one time step, the deposition decay rate will differ from species to species but only in the factor $V_{d}$ (sce $\mathrm{Eq}$. 2), while the radiological or chemical decay factor will, in general, differ from species to species, although for any given species it will be the same for all time steps. In what follows, the discussion will apply to a single time step, and the indices will therefore refer to the members of the decay chain. 


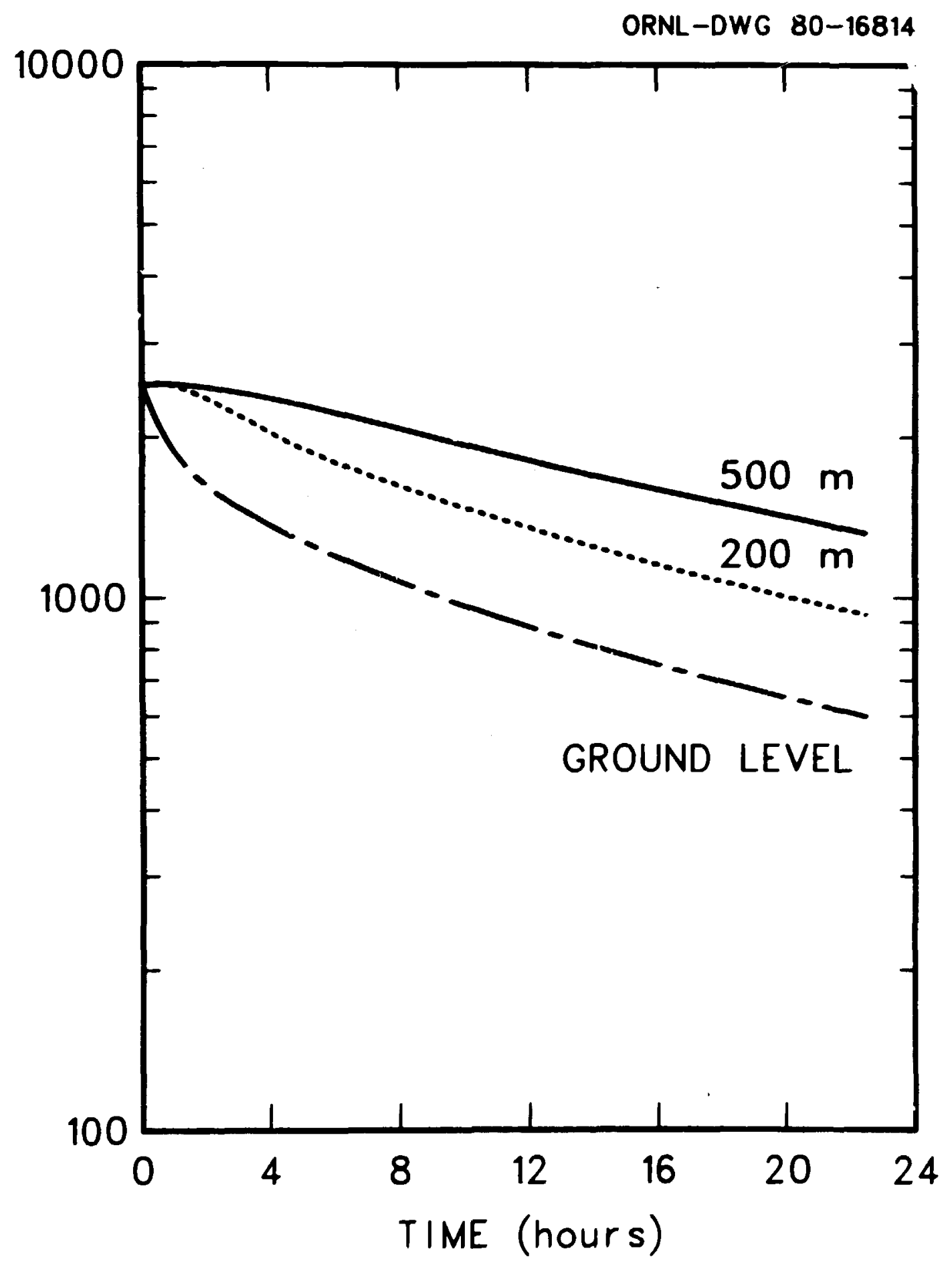

Fig. 3. Plume strength as a function of travel time for sources at various heights. Note that the plume strength of the ground level source is strongly depleted in the early stages of travel. 
For the first member of a chain one has that

$$
\frac{d Q_{1}}{d t}=-\lambda_{1} Q_{1}
$$

Now, the second member of the chain is fed from the decay of the first member. Therefore,

$$
\frac{d Q_{2}}{d t}=s_{21} Q_{1}-\lambda_{2} Q_{2}
$$

where $s_{21}=r_{21} \lambda_{1}^{\prime}$ in which $r_{21}$ is the branching fraction from species 1 to species 2 and $\lambda !$ is the radiological (or chemical) decay constant for species number $l$.

The equations so far have referred to amount of material, i.e., they deal with source strength which is proportional to, $\mathbf{N}$ the number of nuclei of a given species. However, for the case of radionuclides, it is more convenient to work in activity units. Since the activity of species $i$ is $A_{i}=\lambda_{i} N_{i}$, if one replaces the Q's in Eq. (11) by the corresponding A's it then follows that $s_{21}=r_{21} \lambda_{2}^{r}$.

In general, therefore,

$$
\frac{d Q_{i}}{d t}=s_{t, j-1} Q_{i-1}-\lambda_{i} \dot{Q}_{i}
$$

or

$$
\frac{d A_{i}}{d t}=s_{i, j-1} A_{i-1}-\lambda_{i} A_{i}
$$

where one uses the appropriate expression !or $s_{i, j-1}$.

We can thus include all removal processes (dry deposition, wet deposition, radioactive decay, and chemical transformation) and derive a set of decay and growth equations. These are well known and solvable; the first solution may have been Bateman's (1910). The solution has more recently been discussed by Skrable (1974).

Starting with $Q_{1}^{0}$ at time zero, the solution for $Q_{i 1}$ at time $t$ is:

$$
Q_{n}=\left(C_{1} e^{-\lambda_{1} s}+----+C_{n} e^{-\lambda_{1}^{\prime}}\right) Q_{1}^{0}
$$

where

$$
C_{i}=\frac{\prod_{j=2}^{n} s_{j j-1}}{\prod_{j \neq i}\left(\lambda_{j}-\lambda_{i}\right)}
$$

This solution can be applied to a decay chain of arbitrary length. The procedure can be repeated for each species which is present at the beginning of a time interval. 


\section{OUTLINE OF THE RETADD-II CODE}

In this chapter the overall operation of RETADD is described. Input and output aspects of the program are described in more de:ail in a later chapter.

RETADD-II is an expanded version of RETADD (Begovich, Murphy, and Nappo, 1978). It differs from the latter in its ability to handle elevated sources, decay chains of related pollutant species, and in its formalism for incorporating deposition decay.

The code (written in FORTRAN-IV) described here nas been developed on an IBM 3033 machine. Discussion of input and output features will therefore be in the context of such a machine. However, the code has otherwise been structured so as to be as transportable as possible. Non standard coding has been avoided.

RETADD-II calcuiates atmospheric dispersion using historical wind data. Thus, there is an inherent assumption that in predicting dispersion conditions for some future time, past wind data wo.ld likely be representative of that future time period. For instance, if one were to model the situation likely to occur during the month of July one siould use data for a July considered to be typical. If resources would allow one could perhaps do the calculation for a number of past Julys and then average the results.

RETADD-II is controlled by a driver routine (MAIN). This driver routine invokes a number of subroutines which perform the foliowing functions:

i. Input of data which describe conditions under which the model is to be run.

ii. Locating and reading of upper-air wind data stored on tape or disk. These upper air wind data are stored in chronological order and new data are read from time to time as the model proceeds with the simulation.

iii. Interpolation of wind vectors using these wind data and construction of trajectory segments using the interpolated wind vectors.

iv. Concatenating a series of sequential segments to produce wind trajectories which originate at a source of atmosphere emissions. If one were only i.terested ir having information on wind trajectories the code can terminate here by displaying the trajectories. However, one is normally interested in the dispersion of the emitted material. In that case the trajectory information is stored and the program proceeds.

v. Using data on decay rates (chemical or radioactive), dry deposition and wet deposition to compute the plume strengths of the output material and its daughter products as a function of travel time.

vi. Using these plume strength estimates together with trajectory locations, to calculate ground level corrcentration and deposition rates for the primary and successor species.

\section{TRAJECTORY CALCULATIONS}

The model calculates dispersion from a source located within a rectangular area specified by the user. The first step in this calculation is the determination of the trajectories of plumes originating at the source. Trajectories are computed which originate at the source every 6 hours, i.e., four trajectories are started per day at $0 Z, 6 Z, 12 Z$, and $18 Z$. These trajectories are composed of three-hour segments obtained from wind vectors calculated at $0 Z, 3 Z, 6 Z, 9 Z$, etc. The upper-air wind data used by RETADD-II refer to $0 Z, 6 Z$, $12 Z$, and $18 Z$. A wind vector at a given location is calculated by interpolation of wind observations at nearby stations. This interpolation process will now be described.

In the description that follows the actual FORTRAN names of quantities appearing in the calculation will be used.

The observed wind data consist of wind speed and direction at varying heights for different weather stations. Data for a particular station are used if its location is within certain boundaries. The $x$ and $y$ components of the wind at each level are determined by vector decomposition, (for the purpose of the following discussion, the $x$ and $y$ directions refer to the eastward and northward directions, respectively; i.e., the conventional $x$ and $y$ axes as one looks at a map). The components are then averaged over all heights which are within a specified depth of the boundary layer so as to produce a layer-averaged wind vector for a 
particular station:

$$
\begin{aligned}
& \text { XAW }=\text { STHXW/STH } \\
& \text { YAW }=\text { STHYW/STH }
\end{aligned}
$$

\begin{tabular}{|c|c|c|}
\hline & & \\
\hline & & $\begin{array}{l}\text { summation of the product of level depth (midpoint to midpoint } \\
\text { except at edges) and } x \text { or } y \text { wind component, respectively, at that } \\
\text { depth }\left(\mathrm{m}^{2} / \mathrm{sec}\right) \text {. } \\
\text { summation of level depths }(\mathrm{m}) \text {. }\end{array}$ \\
\hline
\end{tabular}

where

In determining a trajertory segment, the layer-averaged wind vectors are used and a wind vector is interpolated for the originating point of the segment. The layer-averaged wind vector for each station is weighted according to a distance factor and an alignment factor. The distanse factor gives more weight to the closest stations. The alignment factor gives more weight to wind observation directly upwind or duwnwind. The calculation of the distance and alignment factors can be understood by referring to Fig. 4.

The distance factor, DISTW, is calculated as follows:

$$
\begin{aligned}
& \mathbf{X W}=-\mathbf{X}+\mathbf{X T S} / 2 \\
& \mathbf{Y W}=\mathbf{Y}-\mathbf{Y T S} / 2 \\
& \text { DWSQ }=\mathbf{X W} \mathbf{X W}+\mathbf{Y W} * \mathbf{Y W} \\
& \text { DISTW }=1 . / D W S Q
\end{aligned}
$$

where,

$\mathrm{X}, \mathrm{Y}=$ distance in $\mathrm{x}$ and $\mathrm{y}$ direction from trajectory segment urigin to weather station, ( arc),

$X T S, Y T_{3}=$ distance in the $\mathrm{x}$ and $\mathrm{y}$ direction that the wind recorded at that station will travel during trajectury segment duration, ( arc).

The alignment fartor, ALINW, is calculated by:

$$
\begin{array}{ll}
\mathrm{D} & =\mathrm{SQRT}(\mathrm{X} * \mathrm{X}+\mathrm{Y} * \mathrm{Y}) \\
\mathrm{DTS} & =\mathrm{SQRT}(\mathrm{XTS} \times \mathrm{XTS}+\mathrm{YTS} * \mathrm{YTS}) \\
\text { ALINW } & =1 .-5 * \text { ABS }(Y T S * \mathrm{X} \cdot \mathrm{XTS} * \mathrm{Y}) / D T S * \mathrm{D}))
\end{array}
$$

where

D = distance from trajectory segment origin to weather station, ( arc), DTS = travel distance of wind recorded for trajectory duration, $(\dot{a r c})$, $X, Y, X T S, Y T S$ are as defined above. 


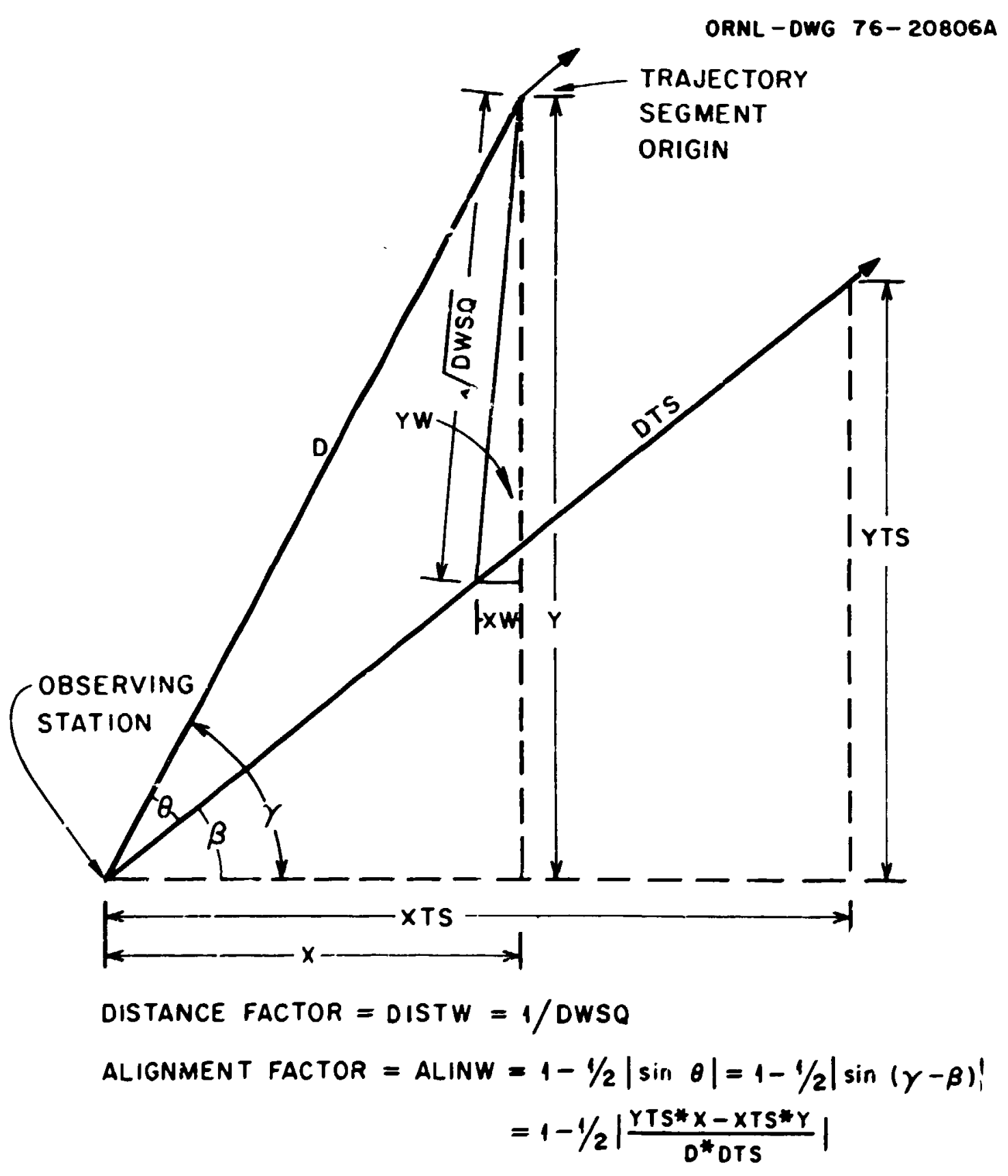

Fig. 4. Geometry of Distance and Alignment Factor calculation 
The displacement of the trajectory is then calculated by averaging over all staticns:

$$
\begin{aligned}
& \text { XTS }=\text { SWXTSI/SWI } \\
& \text { YTS }=\text { SWYTSI/SWI }
\end{aligned}
$$

where

$$
\begin{aligned}
& \text { XTS,YTS } \\
& \text { SWXTSI,SWYTSi }=
\end{aligned}
$$

The position of the trajectory segenent is updated, and an average velocity for this time perod is determined.

When calculating the trajectory displacements, it is required that at least two weather stations be within a radius of 300 nautical miles of the segment origin or one station be within one-balf of this radius. If the data do not meet these distance specifications for a partisular segment, then the data for the closest time period are used. If in turn, this condition is not met, the data from the second closest time period are used. Finally, if none of these three observations contains enough data, the trajectory is terminared.

$\mathrm{On}$ any given day the wind vector for $\mathrm{OZ}$ at the source is calculated using the $\mathrm{OZ}$ upper-air wind data. This gives a ?-hour trajectory segment. Now, using the $6 Z$ upper-air wind data a new $3 Z$ wind vector is calculated for the end point location of this 3-hour trajectory segment. Using this new wind vector another 3 hour trajectiory sejment is calculated to yield the end point of the trajectory after 6 hours i.e. at $6 Z$. Again, using the $u Z$ upper-air wind data another 3-hour trajectory segment is appended to bring the trajectory to $9 \mathrm{Z}$. This process is continued for a length of time specified by the user. This length of time should be chosen such that it is sufficient to produce a trajectory which goes outside the boundaries of the study area (if o trajectory were 'o re-enter the study area such an event would go unnoticed!). This whole process is repeated for a trajectory originating at the source at $6 Z$ and so on at 6 hourly intervals for the duration of the simulation time.

In summary the data are used as follows to calculate trajectory segments:

Data at $\mathrm{OZ}$ used for segments between $\mathrm{O}$ and 3 hours

Data at $6 Z$ used for segments between 3 and 6 hours Data at $6 Z$ used for ssgments between 6 and 9 hours

Data at $12 Z$ used for segments between 9 and 12 hours Datr at $! 2 Z$ used for segments between 12 and 15 hours

Data a: 182 used for segments between 15 and 18 hours Data at $18 Z$ used for segments between 18 and 21 hours

Data at $0 Z$ used for segments between 21 and 24 hours

The optional printed output of the wind trajectory part of the program includes two tables and trajectory plots. The first table indicates the number of weather stations used to determine the trajectory displacements at each step. To the right of each number, if a "+" or a "-" appears, the data closest or second closest in ime were used, respectively. The second table lists the trajectory segment endpoints for every 12 hours. Additional output which lists input wind data is printeat if the user requests it.

Trajectory plots are printed for each day. Four trajectories are indicated in each plot, beginning or cnding at $0 \mathrm{Z}, 600 \mathrm{Z}, 1200 \mathrm{Z}, 1800 \mathrm{Z}$. Each of these is plotted for the duration of the trajectory. 


\section{PLUME STRENGTH CALCULATIOMS}

As noted, effective decay rates for dry deposition are next calculated for each 3-hour trajectory segment. A decay rate must be calculated for each species in the plume. However, as can be seen from Eq. 2 the major part of ti.e plume depletion depends on geometric factors and once calculated for any given trajectory segment, depletion rates for different species within that plume are obtained via a multiplication using the appropriate deposition velocity, $V_{d}$. The effective plume deca; rates for each plume segment and for each species are determined in the subroutine DEPLAM.

At a point sufficiently downwind from the source the plume will become uniformly mixed throughout the mixed layer. Under those circumstances source depletion can be assumed to proceed in a truly exponential manner with the removal rate constant being $V_{d} / L$ where $L$ is the depth of the mixed layer. It is assumed in subroutine DEPLAM that this situation comes about when $\sigma_{z}=0.94 \mathrm{~L}$ (see, c.g., Turner, 1970). However, it is also assumed that the restricting effects of the mixed layer will begin to be felt when $\sigma_{z}=0.47 \mathrm{~L}$. Thus for $\sigma_{x}<0.4 \mathrm{iL}$ the formalism outlined Eqs. (1) $-(6)$ is employed. For $\sigma_{z}>0.94 \mathrm{~L}$ it is assumed that $\lambda^{d}=V_{d} / L$. For $0.47 \mathrm{~L}<\sigma_{z}<0.94 \mathrm{~L}$ a weighted linear combination of these two mechanisms is empluyed.

Having the effective dzcay rate due to dry deposition the program proceeds to invoke the subroutine DECAY which takes account of all depletion processes and calculates plume strengths for all species and for all trajectory segments. The subroutine DECAY has been coded in double precision. All other parts of RETADD-II are single precision, however. Subroutine DECAY is contained in a loop which starts with the plume strength for each species in the plume at the time of emission. Plume strength at the time of emission is by definition the amount of material emitted per second by the siurce. In many cases this will be non zero for the parent species only. Plume strength will vary in time for the different species which may be in the piume by virtue of decay or ingrowth processes. The subroutine DECAY calculates plume strengths for the midpoint of each trajectory segment sequentially using the plume strengths at the time of emission as starting values. Dry deposition decay, wet deposition decay, and radioactive or chemical decay are considered using the formalism outlined in Egs. (8) - (13). Since chemical species would be dealt with in terms of mass per unit volume one must take account of changes in molecular weight from species to species throughout a decay chain.

\section{ATMOSPHERIC DISPERSION CALCULATIONS}

The subroutine CPLOT controls the calculation and lineprinter plotting of atmospheric ground level concentration or activity and deposition rates of amount of mass or activity. Informaiion on trajectory segment locations and plume strength are used together with horizontal and vertical diffusion rates in these calculations. Ground level concentration is calculated using a standard Gaussian plume formula

$$
x=\frac{Q(t)}{\pi \sigma_{y} \sigma_{z} u} \exp \left\{-1 / 2\left(\frac{y}{\sigma_{y}}\right)^{\eta}\right\} \exp \left\{-1 / 2\left(\frac{h}{\sigma_{z}}\right)^{\eta}\right\}
$$

which is the same as Eq. (1) except that it is now written such that the plume strength, $Q$, is a function of time. By suitable choice of the input coefficients, $Q$ can be expressed in terms of either mass or activity units.

All Gaussian plume calculations are handled in the subroutine SPREAD which is called by CPLOT. SPREAD fills an array $G$ with the ground level activity or concentration values having determined lateral and vertical diffusion rates and using plume strengeh values calculated by DECAY. This process is executed for each species in the decay c'rain.

The vertical spread of the plume is determined from $\sigma_{2}=\left(2 K_{2} l\right)^{1 / 4}$ where the value of $K_{z}$ can be specified by the user. If a value is not entered for $K_{z}$ a default value of $15 \mathrm{~m}^{2} / \mathrm{s}$ is used (Draxler, 1979).

The horizontal spread of the plume is given by the relationship $n_{y}$ (meters) $=0.5 t($ seconds). This is a simple fit to a large amount of datz presented by Heffer (1965). 
The array $\mathbf{G}$ is used to produce line printer plots of ground level atmospheric activity (or concentration) and of deposition rates to the ground. The spatial resolution implied by the array $G$ is, of course, much superior to that which is actually obtainable in a typical application of this code and it should be kept in mind that the array $G$ is only used for display purposes. Although the array $G$ is dimensioned $126 \times 60$ it contains only $63 \times 30$ separate values.

Results obtained from RETADD are output in an array GRNDP dimensioned (2! $x$ 15). This array is obtained by consolidating groups of $(6 \times 4)$ of the cells in the array $G$, which actually means that groups of $(3 \times 2)$ separate values are combined.

\section{DEPOSITION CALCULATIONS}

Ground deposition is calculated as total deposition, i.e dry deposition plus wet deposition. Deposition per unit time is obtained by multiplying the average ground level activity (or concentration) by the deposition velocity.

It is necessary to specify a dry deposition velocity when exercising RETADD. Dry deposition velocities are not always known very accurately but in many cases a literature search may give a reasonable indication of the range of values which may be appropriate. It is left to the model user to decide what is an appropriate value.

Wet deposition is estimated from the wet deposition velocity. As discussed above, the wet deposition velocity is calculated as

$$
V_{\omega}=W_{r} P
$$

where $W$, is the washout ratio for the species of interest (supplied as input data) and $\mathrm{P}$ is the average precipitation rate. If zero is entered for $W$, in the case of any species the program will use a value of $4.2 \times 10^{5}$ (Englemann, 1970).

Although precipi ation patterns are of importance in determining wet deposition, in practice, one is limited to using the average precipitation rate for a region. Precipitation patterns vary from place to place and from year to year but when determining average deposition patterns then the average precipitation rate is most appropriate.

\section{CALCULATIONAL GRID SYSTEMS}

RETADD-II displays the calculated trajectories, grand level air concentration (or activity) and deposition rates as line printer plots. These plots are produced for display on a line printer page using, 126 horizontal characters and 60 vertical characters. This is done solely for display purposes. We do not mean tc imply that the spatial resolution of the model is consistent with a $126 \times 60$ cell grid (when calculating for the continental U.S., for instance, a maximum of 100 upper air wind stations is typical).

Having obtained ground level concentrations on a $126 \times 60$ grid for display purposes a conversion is made to a coarser grid for output purposes. These output data are stored for later use by another model such as TERRA (Baes et al., to be published). This final output grid is of $21 \times 15$ cells and the values for this grid are obtained by averaging over groups of $6 \times 4$ cells on the $126 \times 60$ grid. The output from RETADD-II is based on a Mercator projection. Specifically, all grid cells wnuld be of the same size when viewed on a map based on a Mercator projection. Thus, the width of all cells will be the saine in terms of longitude increment, whereas the latitude increment corresponding to a cell height will be longer towards the equator.

\section{DATA INPUT}

Two type : of data are needed to run the model. Upper-air wind data are uned to calculat: the location and direction of trajectory segments and control data are used to descrite the conditions under which the model is to be run. The wind data are stored on tapes from which they can be read as needed. Alternatively the data can be temporarily stored on Jisk from which they can be easily read. The organization of the upper-air wind data is described in Appendix A. We will now proceed to discuss the control data which are input to RETADD as cards. Appendix B contains an example of a card ir.put stream. 
Card No. 1 contains a title and is read as 80Al.

Card No. 2 ider.cifies the source with an identifier OID (can be left blank) and the latitude and longitude, OLAT and ULON in degrees (as constructed the code interprets all longitude values as being West longitude. i.e., value increases to the West). These three items are read as A8,1X,F5.1,1X,F6.1.

Card No. 3 contains information on the day (IBDY), month (SIBMO) and year (IBYR) that computation is to hegin and the number of days (NDY) for which computations are to be performed. These are read in as I2, IX, A3, IX, I2, IX, I2. Note, the month is read in as A3, i.e., the first three letters of the name of the month, JAN, FEB, MAR, etc. The year is read simply as two digits, e.g., 75, 76, etc. The wind data being read from tape or disk must sorrespond to the year being requested. If this is not the case then the job will abort.

Card No. 4 gives the desired trajectory duration in days NDYDUR (read as I2). NDYDUR in the cede described here cannot be greater than 5. To increase this maximum value will require more storage. However, in principle, there are no other impediments to doing so. NDYDUR describes the length of time, in days, for which each originating trajectory is followed. The code follows trajectories originating every six hours and each one of these is followed for a length of time equal to NDYDUR. NDYDUR should be long enough so that, in general, it succeeds in advecting material out of the region of interest or that it corresponds to a distance at which concentrations are low enough to be of little interest.

Card No. 5 controls the form of output to be obtained from RETADD-II. Five quantities ITPLT, ICPLT, IPRNT. IPNCH and IAND are read in as 5I5. If this card is left blank, or if zeros are entered for all quantities one oblains the default options which are considered to be the most likely to be requested. Individually, however, these options work as follows: If ITPLT $=0$, the trajectories, when calculated, are plotted on a line printer map. If ICPLT $=0$ then the program proceeds to subroutine CPLOT which means that the diffusion calculations are performed and ground level atmospheric activities or concentrations are calculated for the various species of interest. If ICPLT has any other value, the code, having calculated all of the relevant trajectories, will terminate.

The parameter IPRNT controls the amount of line-printer output from RETADD. If it is set to zero then a minimum of material will be output. Ií a value other than zero is used, information or trajectories will be output which may be useful to a meteorologist.

IPNCH when set to zero will allow the punching of a caid or card image file of the calculated ground level atmospheric activities or concentrations and deposition rates. This file is output on device number 7 and allowance must be made for it in the JCL stream. If IPNCH $=1$, this file will not be created.

When IAND $=0$ the subroutine ANDOUT will be invoked. This will create another card or card image file to be used by the ANDROS code (Begovich, Ohr and Chester, to be published).

Card No. 6 coritains the boundaries of the area of interest in reading wind data. These are DTABT, DTABB, DTABL, DTABR which are respectively the top, bottom, left, and right borders in degrees latitude or longitude as the case may be. Wind data for all stations within these borders will be made available in calculating trajectories. Therefore, these borders should delineate at least the geographic area for which calculations are being done. The four quantities are entered with the format F4.I, IX, F4.1, IX, F6.1, IX, F6.1.

Card No. 7 reads in the following quantities:
LBAAT:
Base of transport layer in meters above average terrain height.
LTAAT: Top of transport layer in meters above average terrain height.
AKZ: Vestical diffusion coefficient in $\mathrm{m}^{2} / \mathrm{s}$ (if this quantity is entered as zero it will be set to $15 \mathrm{~m}^{2} / \mathrm{s}$ in the code).
PR.ECIP: $\quad$ Precipitation rate in inches/year.
DE.LZR: $\quad$ Depth of rain layer in meters (if entered as zero it will be set to $1000 \mathrm{~m}$ ).

These quantities are read in the format I4, IX, I4, IX, 3F 10.4 .

The next card (No. 8) defines the geographic region of interest. This is done by givirig the number of degrees longitude per inch for line priiter plots (XDEGPN) and by giving the latiture (ALATT) and longitude (ALONI) of the northwest corner of the region to be analyzed. The line printer will display 12.6 inches of plot in a horizontal direction so that 12.6 times XDECPN is the number of degrees longitude in the horizontal dirction. The vertical extent of the region will be about half of this in degrees. These quantities are read in the format F5.1, F4.1, IX, F6.1. 
Card No. 9 begins the input of data which are specific to the source and the emissions. On Card No. 9 are contained the number of species to be considered (i.e., the number of members of the decay chain) and the height of the source in meters. These are entered in the format I5, E10.4.

Card No. 10 contains the initial source strengths in the format 8D10.4 (they will be treated as double precision variables). As the code is currently constructed, it can accommodate an eight member chain.

The units in which the source strengths are expressed are entered are on Card No. 11 as a field of 10 characters followed by the variable ICHEM in 12 format. If ICHEM has a value greater than zero the code will treat all decay chain members as chemical species and will calculate concentration; in mass units. If ICHEM is less than or equal to zero, the code assumes radionuclides and calculates all results as activities.

Card No. 12 contains identifier for the members of the decay chain. In general these names should be entered as alphanumeric data. However, in this version of the code which is run in conjunction with the other codes in the CRISS system (Baes \& Miller, 1981) the identifiers should be numeric and in that format they can be used for cross referencing with various data files. These numeric identifiers are basid on the $Z$ and $A$ numbers of the nuclides involved as follows: 10,000 times the $Z$ number +10 times the $A$ number $t$ a digit in the units location which is zero for a ground stat : with non zero for other isomeric states. For instance, the nuciide ${ }^{222} \mathrm{Rn}$ would be assigned the identifier 362220 . These quantities are read in the format 1018.

Card No. 13 contains the decay half-lives of the species identified on card I1. Since decay half lives can spar. a large range of times they can be entered in the units in which they are most familiar. This procedure proves helpful when visualiy inspecting input files. The data elements are entered in the format 8(F7.2,AI) which will be a numeric value followed by a single letter from the set $S, M, H, D, Y$ indicating that the value is in units of seconds, minutes, hours, days or years respectively.

Card No. 14 contains the branching information for each of the nuclides in the chain. This is entered as the percentage decaying to the next member of the chain in the format 10D8.4.

Card No. 15 contains the dry deposition velocities for the species in the chain is $\mathrm{m} / \mathrm{s}$ in the format 10D8.4.

Card No. I6 contains the washout ratios for the members of the chain in the format 10D8.4.

\section{OUTPUT FROM THE RETADD-II CODE}

Besides the numerical zesults produced by the code, some graphical output is available on the line printer. Two types of graphical output can be obtained. For both types a line printer page is used to represent the geographical area being studied. The first type of graphical output displays the wind trajectories being used in the dispersion calculation. One page of output is produced for each day of wind data used, i.e., four trajectories per page. Latitude and longitude values are printed along the top and along the lefthand side of the page for reference purposes.

The second type of graphical output is a line printer density plot which is intended to give a rough visual indication of concentration (or activity) and deposition patterns. One activity or concentration pattern plot and one deposition pattern plot is produced for each species. The f'ots cover the same geographic area as do the trajectory plots and they are similarly identified with latitude and longitude values.

Numirical values of activity or concentration and of deposition are produced for the $21 \times 15$ cells of the grid described above. These values are listed on the line printer and are also avaiiable on cards or as card images.

Line printer output is produced as activity and as deposition for each species, i.e., (wo separate sets of output for each species. Each set of output is contained on two pages. The first page contains the 11 western most columns of cells from the grid and the second page will contain the remaining ten columns of cells in the eastern part of the grid.

Punch card or card image output of the concentration and ceposition data is also available. This is written on unit 7 and it is intended as a means by which output data can be stored for later r,rocessing by eisplay routines, for instance This output to unit 7 is not intended for use by other programs in the CRRIS system. To obtain this output the parameter IPNCH should be set to zero in the input stream. The values for the $21 \times 15$ array will be output row by row from north to south. Since each row contains 21 values it is output as three records of seven values (i.e., 7E10.4) which correspond to cells of a given row going from west to east. Each set of output for a given species and concentration or deposition is identified 
by a header record.

Output for further use by codes in the CRRIS system is obtainable on unit 12 and this output is produced by the subroutine ANDOUT.

RETADD can also write the concentration and the deposition values onto a special file to te reau by ANDROS and TERRA. This file consists of five types of record and it is written in unformatted fashion. However, the quantities written have a variety of types associated with them. Some of the variables discussed below are of a non-standard type and when this is the case, the t;pe is explicitly given.

Record 1:

It contains

TITLE(20A4)

GRDOPT(I*4); Grid option, GRDOPT = I for RETADD indicating

rectangular gnr.

IPTOGR; Values are for point or grid IPTOGR $=1$, indicating grid value.

$\operatorname{XREF}\left(R^{*} 8\right)$; $\quad$ Source longitude

YREF $(R * 8)$; $\quad$ Source latitude

$\operatorname{RLOC}(\mathbf{R} * 8)$; $\quad$ Not relevant to RETADD-II

IHLOC $(R * 8) ; \quad N_{i}$ relevant to RETADD-II

XDIFF $(R * 8)$; $\quad$ Not relevant to RETADD-II

YDIFF $(R * 8)$; $\quad$ Not relevant to RETADD-II

UNIT;

Source emission units (e.g., $\mathrm{Ci} / \mathrm{s}$ or $\mathrm{Bq} / \mathrm{s}$ ).

NLOC; $\quad$ No. of locations for which values are output. For RETADD

$\mathrm{NLOC}=315$.

Record 2: $\quad$ ICODE, ICODE $=1$, for RETADD

IOPT,(I3(I*4)); Not relevant to RETADD-II

Record 3: This record has the information abuut the following

NC; $\quad$ No. of released nuclides

ZASRN; $\quad$ ZAS numbers for the released nuclides

NREXP; $\quad$ No. of exposure nuclides

Z.ASEN; $\quad$ ZAS numbers for exposure nuclides

Record 4: There are NLOC of Record 4. Each specifies the boundary of a grid cell and number of indicators for which the value is given. Indicators refer to types of output. For RETADD-II, two types are possible, ground level concentration (or exposure) and deposition.

XMIN; $\quad$ Left longitude of the grid in degrees (West longitude).

XMAX; $\quad$ Right longitude of the grid in degrees (West longitude).

YMIN; $\quad$ Bottom latitude of the grid in degrees (North latitude).

YMAX; $\quad$ Top latitude of the grid in degrees (North latitude).

NIND; $\quad$ No. of indicators given. For RETADD, NIND is always 2.

Record 5: There are NIND of record 5 for each grid cell listed in Racord 4. It contains

IND; $\quad$ Indicates the quantities to which the output values refer.

IND $=1$ for concentration valies

IK;

IND $=10$ for deposition values

$(\mathrm{CONC}(\mathrm{N}), \mathrm{N}=\mathrm{I}, \mathrm{IK}) ; \quad$ Concentration values for each nuclide. 
Record 5A: Assiming that plume material in the atmosphere is attachrd to particulate matter, Record SA contains data on that particulate matter.

(PSZ(N),N=1,IK); Particle sizes for species (in microns).

$(\mathrm{CLS}(\mathrm{N}, \mathrm{M}), \mathrm{M}=1,4, \mathrm{~N}=1, \mathrm{IK}$ );

Fraction of species in each clearance class.

Clearance classes are for

$M=1$; for $D$ (clearance half times of less than one day).

$M=2$ : for $W$ (clearance half times of a few days to a few months).

$M=3$; for $Y$ (clearance half times of six months to several years).

$M=4$; for * (a gaseous material).

\section{DISCUSSION OF THE RETADD-II SUBROUTINES}

Figure 5 is a schematic of the structure of RETADD-il. A brief description will be given here of the various parts of the code and of their interrelationships.

INPUT reads the control data for a given run, i.e., all data other than the upper-air wind data contained on a tape or disk file. POSTP then searches the appropriate tape or disk file for the location of the beginning of the upper-air data of interest. TPREAD is called at this point and the initial upper-air data are read. These initial data being read correspond to the upper-air data at $\mathrm{OZ}$ on the first day of the simulation.

DTABKO is called once for each day of the simulation. Each time it is called, it fills a data block with the wind information needed to follow each of the four trajectories originating on that day for the duration specified in the control data. DTABKO calls RJAVO whuse purpose is to read and average the wind data. The data are read by calling TPREAD and at each reporting station a wind vector averaged over the depith of the transport layer (which is user-specified) is produced by the subroutine AWIND.

The code then procends to construct trajectories. A particular day has been focused on by DTABKO. RETADD-II loops over the four trajectories originating that day and for each trajectory it loops over the number of trajectory segments required to reach the duration of the trajectory. During this process a number of routines are called:

KKMM keeps track of the time of day and the trajectory segment.

DISO determines the displacement corresponding to a particular trajectory segment, i.e., it calculates how fas the centroid of a puff would be advected during a particular three hour time interval. In dning this, DISO calls ITSIW which determines which layer-averaged wind vectors to use and and how to weight their contributions.

If there is a shortage of wind data ALTDTA determines how to make use of alternate data and CLSTM controls the acquisition of wind data at the closest availabie observation time.

Having calculated and stored all trajectory segment information, NSPTS can be used to print data on the reporting stations; TSLL can be used to print trajectory segment latitudes and longitudes and TPLOT can be used to produce line printer plots of the trajectories. In outputting this information on trajectory segments the subroutine DATE is used to keep track of the date and NWMOYR is used if the simulaticn period involves changing to a new month or year.

At this point, having calculated the trajectory parameters the code proceeds to deal with the dispersion process. DEPLAM is called and it calculates effective decay constants for the dry deposition process occurring during a given trajectory segment, i.e., as a funcision of travel time.

The subroutine DECAY makes use of all decay constanis and it calculates amount of remaining piu'ne material (and ingrowth of new material) for all plume specics and for each segment of a trajectery.

The subroutine CPLOT handles the task of calculating atmospheric dispers on. CPLOT also writes all output files with the exception of those to be used in the code ANDROS. In calculating the Gaussian spread around the trajectory centerline, CYLOT calls the subroutine SPREAD. Line printer plots of concentration and deposition patterns are also produced by CPLOT and calls to DSP and SCALE are used in producing these plots.

Firrally the subroutine ANDOUT is called which writes sutput files for later use by the ANDROS code. 


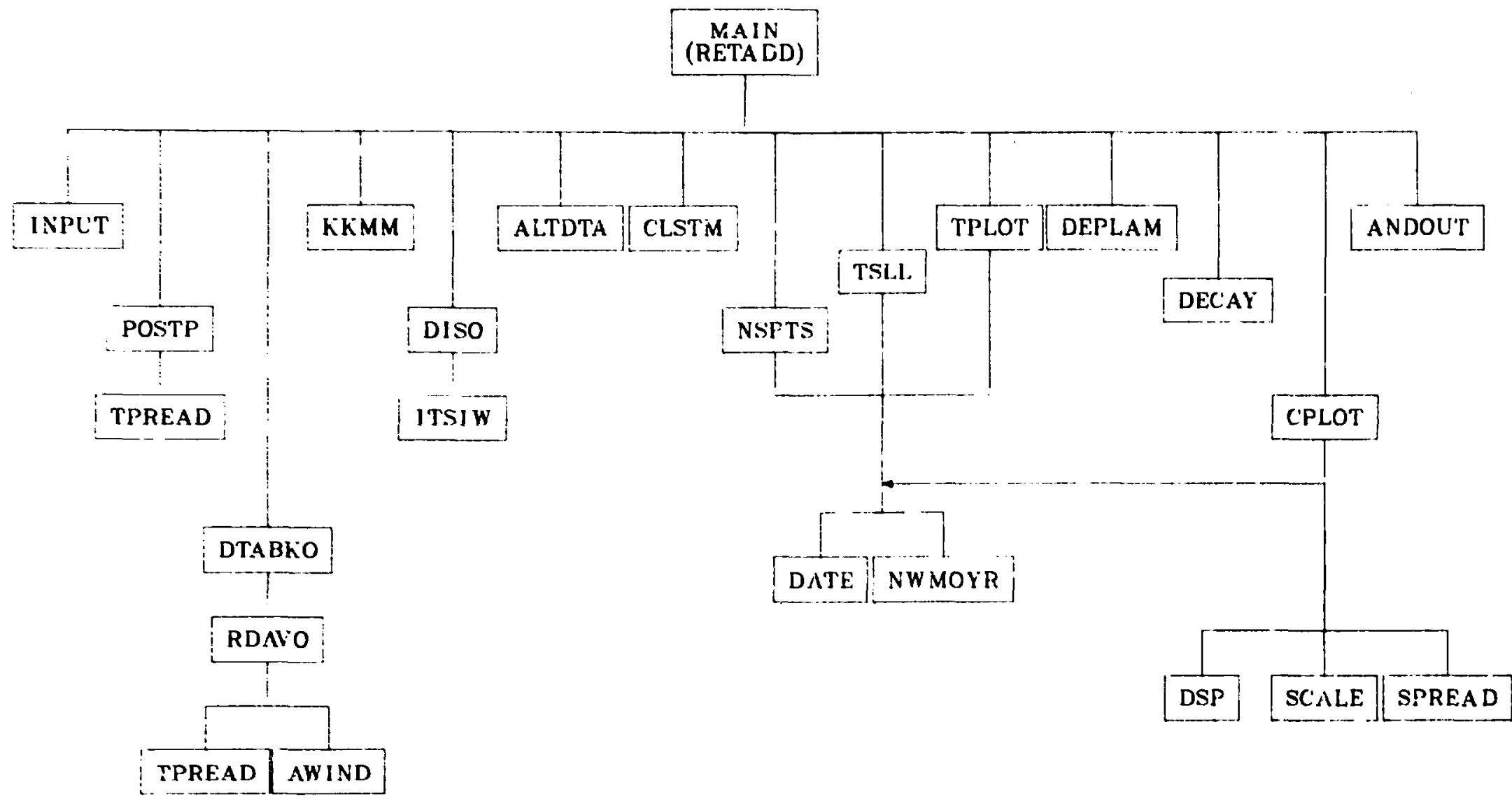

Fig. 5. The subprograms of the RETADD code. 


\section{APPENDIX A}

\section{Storage Format of Uper-Air Whed Data}

RETADD-II calculates trajectories using upper air wind data as reported by weather stations at six hour intervals. These data are normally stored on 6250 bpi magnetic tapes. Each tape contains a year's data.

In the explanation that follows, it is understood that an IBM machine is being used. Thus, words are of 32 bits in length (four bytes) and REAL*4 and INTEGER*4 are the normal size for REAL and INTEGER quantities.

These wind data will have been obtained at four reporting times per day. For each reporting time there are two records on the tape. The first record is a uumber indicating the number of words in the second record. Having read the first record, Subroutine TPREAD then reads all of the second record so that all of the data for a given observation time will be in storage when needed. The second record contains the data labelled by a system of identifying words. A more complete explanation folk is:

Record 1

Length: Ten words

Only the first word contains information. It indicates the number of words in Record 2.

Record 2

Length: Up to 51156 words

The first si: words have the following meanings:

SIDMO:(R*4) Three characters identifying the month.

IDYR:(I*4) Year identification

IDDY:(I*4) Day identification

IDHR:(I*4) The hour at which the observations occurred $(0,6,12$, or 18$)$.

NRSTA:(I*4) Number of reporting stations

NREC:(I*4) Total number of wind information entries for this reporting period

The information for zach of the NRSTA stations then follows.

Each Station is characlcized by six words:

SID:(I*4) A six digit station identification number

SLAT: Latitude of station in degrees North.

SLON: Longitude of station in degrees West.

SHT: Station height in meters.

SATH: Station average teraain height in meters.

NLVL: Number of levels at which wind is recorded.

The data reported by each station then take the following form, which is repeated as many times as indicated by NLVL.

WHT: Height of level in meters.

WDIR: Direction of wind in degrees clockwise from North.

WSPD: Speed of wind in meters per second.

RETADD acquires the starting date for the trajectory calculation from the inn1:i data. Using subroutine POSTP, RETADD searches through the tape $=1 \mathrm{c}$ positions it at the specified starting date. Subroutine TPREAD proceeds to read, one entry at a cime, the starting and subsequent time entries as needed. 


\section{APPENDIX B}

\section{Sanple Ireat Data}

The data below show an example of the input to RETADD-II. These comprise the input other than the upper-air data which are read from tape.

The example shown refers to the emission of ${ }^{222} \mathrm{Rn}$ from a site in the western U.S. The other members of the decay chain being considered are ${ }^{218} \mathrm{Po},{ }^{214} \mathrm{~Pb},{ }^{214} \mathrm{Bi}$ and ${ }^{210} \mathrm{~Pb}$. Their half lives and branching ratios are given and only in the case of the Lead isotopes is there a deposition velocity quoted. Note that in this particular decay chain a sixth species $\left({ }^{214} \mathrm{Po}\right)$ exists between ${ }^{214} \mathrm{Bi}$ and ${ }^{210} \mathrm{~Pb}$. However, since its half life is on the order of $10^{-4} \mathrm{~s}$ it is not considered. See Kocher (1981) for detailed data on decay chains.

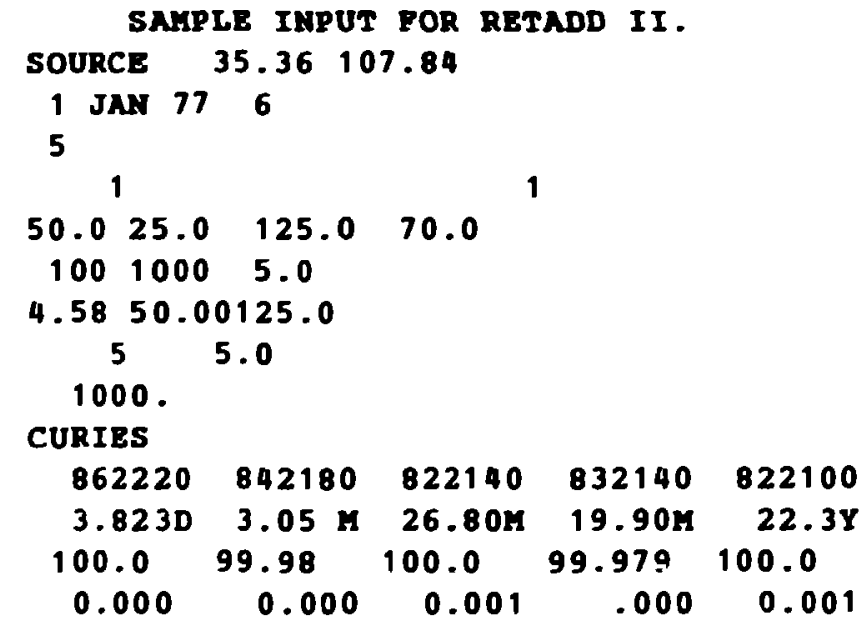




\section{APPENDIX C}

\section{Sample of JCL and with RETADD-I}

A sample of a JCL stream used in executing RETADD-II is reproduced below. Comments have been added. However, the following points should be noted: The output to unit 12 is for use at a later stage by other codes in the CRRIS system. This output is to a mass storage device. As a precaution, a preliminary step is inserted to remove any lata set which may have the same data set name. Output to unit 7 is punch card output (in this example it will be as card inages which are routed back to a storage area on a PDP. 10). Unit 11 is used for temporary storage oi data. Some values calculated during execution are later used by the subroutine ANDOUT and these values are temporarily stored on unit 11 .

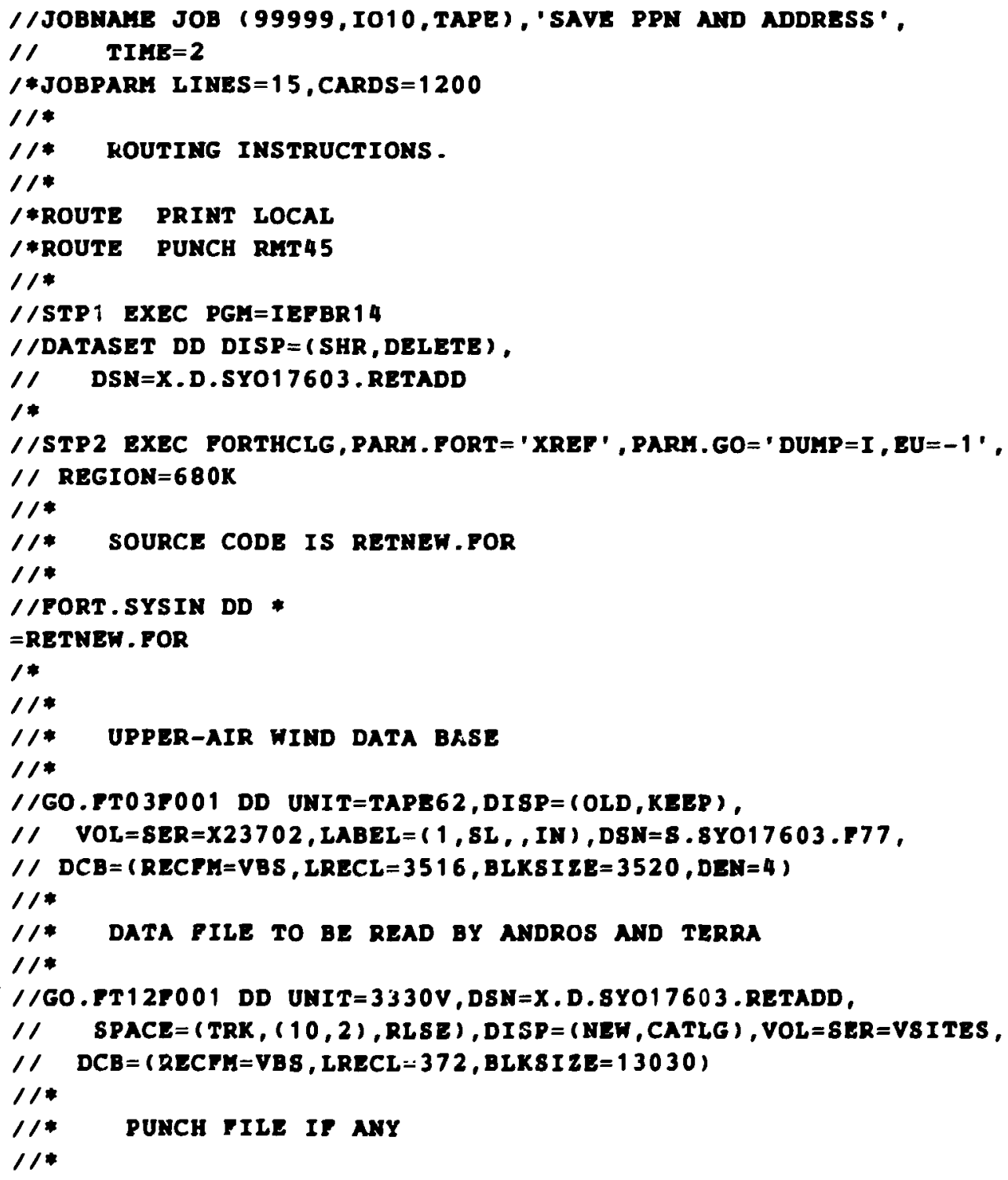


$/ / G 0$. FTO7F00 1 DD SYSOUT=B, $\mathrm{DCB}=(\mathrm{RBCPH}=\mathrm{FB}, \mathrm{LRBCL}=80, \mathrm{BLKSIZB}=3520)$

$1 / *$

$1 /$ t THPORARY STORAGE FILE

$11 *$

$/ / G 0 . F T 117001$ DD UXIT=SYSDA, SPACE $=(\operatorname{TRK},(30,5))$

$11 *$

. $/$ IAPUT FILE TO RETADD IS RETKEH.DAT

$11 *$

$/ /$ GO. PT05P001 DD *

$=$ RSTMEN.DAT

$1 *$

17

BADIMPUT 


\section{REFERENCES}

Baes, C. F. III; Sharp, R. D.; Sjoreen, A. L; and Hermann, O. W., TERRA: A Computer Code for Calculation of the Transport of Environmentally Released Radionuclides Through Agriculture, ORNL. 5785 (to be published).

Baes, C. F. III and Miller, C. W., "CRRIS: A Computerized Methodology for Assessing the Human Impact of Radionuclides Released to the Atmosphere," presented at the 26th Anival Meeting of the Health Physics Society, Louisville, Ky., June 21-26, 1981.

Bass, A., "Modeling Long-Range Transport and Diffusion," AMS/APCA Second Joint Conference on Applications of Air Pollution Meteorology, New Orleans, La., (March 24-27, 1980).

Bateman, H., "The Solution of a System of Differential Equations Occurring in the Theory of Radio-Active Transformations," Proc. Camb. Phil. Soc. 15, 423-427 (1910).

Begovich, C. L.; Murphy, B. D.; and Nappo, C. J., JT., RETADD: A Regional Trajectory and Diffusion Deposition Model, ORNL/TM-5859 (June 1978).

Begovich, C. L.; Ohr, S. Y.; and Chester, R. O., ANDROS: A Code for Assessment of Nuclide Doses and Risk with Option Selections, ORNL-5889 (to be published).

Drax'sr, R. R., -Estimating Vertical Diffusion from Routine Meteorological Tower Measurements" Atmospherit Er:iennment, 13, 1559-1564 (1979).

Eliassen, A., “A Revicw of Long-Range Transport Modeling," J. Appl. Meteor., 19, 231-240 (1980).

Englemann, R. J.. "Scavenging Prediction Using Ratios of Concentrations in Air and in Precipitation," Proc. Symposium on Precipitation Scavenging, AEC Symposium Series 22 (1970).

Fisher, B. E. A., "A Review of the Processes and Models of Long-Range Transport of Air Pollutants," Atmospheric Erri:ronment, 17, 1865-1880 (1983).

Gifford, F. A., "Tropospheric Relative Diffusion Observations" J. Appl. Meteorol. 16, 311-313, (1977).

Hanna, S. R.; Brigge G. A.; and Hosker. R. P., Handbook on Atmospheric Diffusion, TIC, U.S. Dept. of Energy, DOE/TIC-11223, (1982).

Heffter, J. L., "The Variation of Herizontal Diffusion Parameters with Time for Travel Periods of One Hour or Longer," J. Appl. Meteorol. 4, 153-156, (1965).

Heffter, J. L.; Taylor, A. D; and Ferber, G. J., A Regional-Continental Scale Transport, Diffusion, and Deposition Model, NOAA Tech. Memo., ERL ARL-50 (1975).

Heffter, J. L., Air Resources Laboratories Atmospheric Transport and Dispersion Model (ARL-ATAD), NOAA Technical Memorandum, ERL ARL-81, Silver Spring, Md., 1980.

Hermann, O. W.; Baes, C. F. III; Miller, C. W.; Begovich, C. L.; and Sjoreen, A. L., PRIMUS: A Computer Code for the preparation of Radionuclicie Ingrowth Matrices from User-specified Sources. ORNL-5912 (to be published).

Kocher, D. C., 1981. Radioactive Decay Data Tables. U.S. Department of Energy, DOE/TIC-11026. 
Miller, C. W.; Begovich, C. L.; and Hermann, O. W., ANEMOS: A Computer Code to Estimate Air Concentrations and Ground Depasition Rates for Atmospheric Nuclides Emitted from Multiple Operating Sources, ORNL-5913 (to be published).

Murphy, B. D. and Pielson, C. B., The Treatment of Gruund Deposition, Species Decay and Growth and Source Height Effects in a Lagrangian Trajectory Model," Atmospheric Environment, 17, 2545-2547 (1983).

Skrable, K.; French, C.; Chabot, G; and Major, A., "A General Equation for the Kinetics of Linear First Order Phenomena and Suggested Applications," Health Phys., 27, 155-157 (1974).

Slinn, W. G. N., "Parameterizations for Resuspension and for Wet and Dry Deposition of Particles and Gases for Use in Radiation Dose Calculations," Nucl. Safety, 19(2), 205-219 (1978).

Start, G. E. and Wendell, L. L., Regional Effluent Dispersion Calculations Considering Spatial and Temporal Meteorological Variations, NOAA Technical Memorandum, ERL ARL-44, Idaho Falls, Idaho, 1974.

Turner, D. B., Workbook of Atmospheric Dispersion Estimates, USEPA Publication No. AP-26(1967) revised 1970.

Van der Hoven, I. Deposition of Particles and Gases, Meteorology and Atomic Energy, TID-24190, NTIS, Springfield, Virginia, pp. 202-28, 1968. 


\section{INTERNAL DISTRIBUTION}

ORNL/CSD-99

Dist. Categories

UC-11, UC-41

$\begin{aligned} & \text { 1. } \text { C. F. Baes III } \\ & \text { 2-6. } \text { C. L. Begovich } \\ & \text { 7. } \text { B. A. Berven } \\ & \text { 8. } \text { J. L. Bledsoe } \\ & \text { 9. } \text { H. P. Carter/G. E. Whitesides/ } \\ & \text { CS Library } \\ & \text { 10. } \text { R. O. Chester } \\ & \text { 11. } \text { K. F. Eckerman } \\ & \text { 12. } \text { W. Fulkerson } \\ & \text { 13. } \text { R. H. Gardner } \\ & \text { 14. } \text { Uri Gat } \\ & \text { 15. } \text { C. C. Gilmore } \\ & \text { 16. } \text { S. G. Hildebrand } \\ & \text { 17. } \text { F. O. Hoffman } \\ & \text { 18. } \text { J. T. Holdeman } \\ & \text { 19. } \text { S. V. Kaye } \\ & \text { 20. } \text { G. G. Killögh } \\ & \text { 21. } \text { D. C. Kocher } \\ & \text { 22. } \text { F. C. Kornegay } \\ & \text { 23. } \text { G. S. McNeilly } \\ & \text { 24. } \text { B. F. Maskewitz } \\ & \text { 25. } \text { C. W. Miller } \\ & \text { 26-30. } \text { B. D. Murphy } \\ &\end{aligned}$

\author{
31. F. R. O'Donnell \\ 32. T. W. Oakes \\ 33-37. S. Y. Ohr \\ 38. D. C. Parzyck \\ 39. M. R. Patterson \\ 40. R. J. Raridon \\ 41. P. S. Rohwer \\ 42. M. B. Sears \\ 43. R. D. Sharp \\ 44. A. L. Sjoreen \\ 45. G. W. Suter \\ 46. P. J. Walsh \\ 47. J. P. Witherspoon \\ 48. G. T. Yeh \\ 49. M. Yildiran \\ 50. H. E. Zittel \\ 51. Central Research Library \\ 52. Document Reference Section \\ Section Y-12 \\ 53-54. Laboratory Records - (2) \\ 55. Laboratory Records - RC \\ 56. ORNL Patent Section
}

\section{EXTERNAL DISTRIBUTION}

57. L. R. Anspaugh, Lawrence Livermore Laboratory, P.O. Box 808, Livermore, California 94550.

58. D. A. Baker, Battelle-Pacific Northwest Laboratories, P.O. Box 999, Richland, Washington 99352.

59. Arthur Bass, Environmental Research and Tuchnology, Inc., 3 Militia Drive, Lexington, Massachusetts 07142.

60. Wayne L. Bliss, Director, ORP Las Vegas Facility, U.S. Environmental Protection Ágency, P. O. Box 18416, Las Vegas, Nevada 89114.

61. Jon Broadway, Eastern Environmental Radiation Facility, U.S. Environmental Protection Agency, P. O. Box 3009, Montgomery, Alabama 36193.

62. Gordon Burley, Science Advisor, Office of Radiation Programs (ANR -458), 401 M Street, S.W., Washington, D.C. 20460.

63. Hugh W. Church, Sandia Laboratory, Division 5333, Albuquerque, New Mexico 87115.

64. Frank J. Congel, U.S. Nuclear Regulatory Commission, Washington, D.C. 20555.

65. T. V. Crawford, Savannah River Laboratory, Aiken, South Carolina 29801.

66. Phillip A. Cuny, Environmental Studies and Standards Branct. (ANR-461), Office of Radiation Programs, 401 M Street, S.W., Washington, D.C. 20460.

67. Ray Dickson, National Oceanic and Atmospheric Administration, 550 Second Strect, Idaho Falls, Idaho 93401. 
68. William H. Ellett, Chief, Bioeffects Analysis Branch (ANR-461), Office of Radiation Programs, 401 M Street, S. iV., Washington, D.C. 20460.

69. Floyd L. Galpin, Chief, Waste Management and Standards Branch (ANR-460), Office of Radiation Programs, 401 M Street, S.W., Washington, D.C. 20460.

70. F. A. Gifford, Jr., P. O. Box 3185, Oak Ridge, Tennessee 37831.

71. Carl V. Gogolak, U.S. Department of Energy, Environmental Measurement Laboratory, 376 Hudson Street, New York, New York 10014.

72. Richard J. Guimond, Director, Criteria and Standards Division (ANR-460), Office of Radiation Programs, 401 M Street, S.W., Washington, D.C. 20460.

73. J. William Gunter, Chief, Environmental Studies and Standards Branch (ANR-461), Office of Radiation Programs, 401 M Streer, S.W., Washington, D.C. 20460.

74. Gunter Halbritter, Dept. for Applied Systems Analysis, Nuctear Research Center Karlsruhe, D-7500 Karlsruhe, P. O. Box 3640, Federal Republic of Germany.

75. S. R. Hanna, Environmental Research and Technology, Inc., 3 Militia Drive, Lexingion, Massachusetts 07 I42.

76. James M. Hardin, Envirunmental Studies and Standards Branch (ANR-460), Ofice of Radiation Programs, 401 M Street, S.W., Washington, D.C. 20460.

77. J. W. Healy, Health Physics Division, Los Alamos Scientific Laboratory, P.O. Box 1663, Los Alamos, New Mexico 97544.

78. Bruce Hicks, Director, Atmospheric Turbulence and Diffusion Laboratory, National Oceanic and Atmospheric Administration, P. O. Box E, Oak Ridge. Tennessee 37831.

79. Robert J. M. Horton, Health Effects Research Laboratory, U.S. Environmental Protection Agency, Research Triangle Park, North Carolina 27709.

80. David E. Janes, Director, Analysis and Support Division (ANR-461) Environmental Studies and Standards Branch (ANR-460), Office of Radiation Programs, 401 M Street, S.W., Washington, D.C. 20460.

81. J. Arthur Jones, National Radiological Protection Board, Harwell, Didcot, Oxon., U.K.

82. Wayne Lowder, U.S. Department of Energy, Wasinington, D.C. 20545.

83. W. A. Mills, U.S. Nuclear Regulatory Commission, Washington, D.C. 20555.

84. Christopher B. Nelson, Office of Radiation Programs, U.S. Environmental Protection Agency, Washington, D.C. 20460.

85. Neal Nelson, Bioeffects Analysis Branch (ANR-461), Office of Radiation Programs, 401 M Street, S.W., Washington, D.C. 20460.

86. George Oksza-Chocimowski, ORP Las Vegas Facility, U.S. Environmental Protection Agency, P. O. Box 18416, Las Vegas, Nevada 89114.

87. Charles R. Porter, Director, Eastern Environmental Radiation Facility, U.S. Environmental Protection Agency, P. O. Box 18416, Las Vegas, Nevada 89114.

88. Allan C. B. Richardson, Chief, Guides and Criteria Branch (ANR-460), Office of Radiation Programs, 401 M Street, 'j.W., Washington, D.C. 20460.

89. J. N. Rogers, Div. 8324, Sandia Laboratories, Livermore, California 94550.

90. Glen L. Sjoblom, Director, Orfice of Radiation Programs (ANR-458), 401 M Street, S.W., Washington, D.C. 20460.

91. J. K. Soldat, Pacific Northwest Laboratories, Battelle Memorial Institute, Richland, Washington 99352.

92. Robert E. Sullivan, Biceffects Analysis Branch (ANR-461), Office of Radiation Programs, 401 M Street, S.W., Washington, D.C. 20460.

93. D. Bruce Turner, National Oceanic and Atmospheric Administration, Environmental Applications Branch, Meteorology and Assessment Division, U.S. Environmental Protection Agency, Environmental Sciences Research Laboratory, Research Triangle Park, North Carolina 27711.

94. E. C. Watson, Battelle-Pacific Northwest Laboratories, P. O. Box 999, Richland, Washington 99352.

95. F. W. Whicker, Department of Radiology and Radiation Biology, Colorado State University, Fo-: Collins, Colorado 80521. 
98. Office of Assistant Mgr. for Energy Research and Development, DOE/ORO, Oak Ridge, Tennessee 37830.

99-408. Given distribution as shown in DOE/TIC-4500 (Rev. 72), for categories UC-11, Environmental Control Technology and Earth Sciences; UC-41, Health and Safety. 